\title{
Inhibition of the Development of the Cellular Slime Mould Dictyostelium discoideum by $\omega$-Aminocarboxylic Acids
}

\author{
By M. J. NORTH* AND J. M. ASHWORTH \\ Department of Biology, University of Essex, Colchester, Essex $\mathrm{CO}_{4}{ }_{3} \mathrm{SQ}$
}

(Received I9 December I975)

\begin{abstract}
SUMMARY
Four $\omega$-aminocarboxylic acids - $\epsilon$-aminocaproic acid (EACA), trans-4-aminomethylcyclohexane-I-carboxylic acid (t-AMCHA), $p$-aminomethylbenzoic acid (PAMBA) and $\omega$-aminocaprylic acid (OACA) - prevented fruiting body formation of the cellular slime mould Dictyostelium discoideum. At concentrations of $40 \mathrm{~mm}$, $75 \mathrm{mM}$, IO $\mathrm{mm}$ and $5 \mathrm{mM}$, respectively, they allowed aggregation but prevented all further development at $24{ }^{\circ} \mathrm{C}$. At lower concentrations, EACA allowed fruiting body formation but with a reduced number of spores per fruiting body. Only t-AMCHA had a significant inhibitory effect on the growth of myxamoebae. EACA affected development only if it was present between 8 and $\mathrm{I} 6 \mathrm{~h}$ after the cells were deposited on the filters. Its effect was enhanced by high salt concentrations and by higher temperature, and was also dependent on the manner in which the cells were grown. Only strains capable of axenic growth displayed this sensitivity to EACA, although strains carrying only one of the genetic markers for axenic growth (axe $A)$ were partially sensitive.
\end{abstract}

\section{INTRODUCTION}

When myxamoebae of the cellular slime mould Dictyostelium discoideum are starved, they enter the developmental phase of their life-cycle and the free-living myxamoebae aggregate to form a multicellular pseudoplasmodium or grex. The aggregated cells undergo a series of morphological changes which culminate in the formation of a fruiting body consisting of two cell types, stalk cells and spores (Garrod \& Ashworth, 1973; Loomis, 1975). In the analysis of events underlying this developmental programme, inhibitors may be useful in revealing important processes : in this paper we report on a group of agents that apparently block development at an intermediate stage.

During an investigation of the effects of a number of inhibitors of proteolytic activity on the development of $D$. discoideum, it was noted that the antifibrinolytic agent $\epsilon$-aminocaproic acid (Ablondi et al., I959; Alkjaersig, Fletcher \& Sherry, 1959) did not allow development to proceed after aggregation had taken place, although it had no effect on the protein loss which accompanied development (North \& Campbell, 1976). The data presented here show that the effect is not only of interest because it is stage specific, but also because it is related to the ability of strains of $D$. discoideum to grow axenically.

\section{METHODS}

Chemicals. Trans-4-aminomethylcyclohexane-I-carboxylic acid (t-AMCHA, tranexamic acid) was a gift from Kabi Pharmaceuticals, London $\mathrm{W}_{5}$. p-Aminomethylbenzoic acid

* Present address : Biochemistry Laboratories, University of Stirling, Stirling FK9 4LA. 
(PAMBA) was a gift from May \& Baker, Dagenham, Essex, and also from VEB Arzneimittelwerk, Dresden, East Germany. $\beta$-Alanine, $\gamma$-aminobutyric acid (GABA), $\delta$-aminovaleric acid hydrochloride (DAVA), $\epsilon$-aminocaproic acid (EACA), $\omega$-aminocaprylic acid (OACA), L-lysine hydrochloride, DL-norleucine, diaminopimelic acid (DAPA), cycloheximide and streptomycin sulphate were supplied by Sigma. $N$-Methyl- $N^{\prime}$-nitro- $N$-nitrosoguanidine (NTG) was supplied by Koch-Light. All other chemicals were of the highest purity obtainable from Fisons Scientific Apparatus, Loughborough, Leicestershire.

Strains. Unless otherwise indicated, Dictyostelium discoideum strain AX2 (ATCC24397) was used; details of all other strains are provided in the paper.

Growth of myxamoebae. Myxamoebae were grown at $22{ }^{\circ} \mathrm{C}$ in shaken cultures in axenic medium lacking added carbohydrate, as described by Watts \& Ashworth (1970). The effect of various agents on growth was tested by growing myxamoebae in Io $\mathrm{ml}$ filter-sterlized axenic medium containing the particular compound in $50 \mathrm{ml}$ Erlenmeyer flasks. The cultures were inoculated with myxamoebae from an exponentially-growing culture at a density of approximately $3 \times 10^{4}$ cells $\mathrm{ml}^{-1}$, and the change in cell density was followed over a suitable period by counting the cells with a haemocytometer.

Myxamoebae were also grown in shaken cultures in association with Klebsiella aerogenes. Bacteria were grown on SM agar (Sussman, 1966) and harvested into 0.017 M-sodium phosphate buffer $\mathrm{pH} 6 \cdot 0$, to give a density of approximately $5 \times 10^{9}$ bacteria $\mathrm{ml}^{-1}$. The suspension was inoculated with myxamoebae and incubated at $22{ }^{\circ} \mathrm{C}$, as with axenicallygrown cells. This procedure was adapted from the method of Gerisch (1960) described by Every \& Ashworth (1975) for growth on Escherichia coli $\mathrm{B} / \mathrm{r}$. Growth tests were carried out using bacteria resuspended in sodium phosphate buffer containing the compound to be tested.

Differentiation of myxamoebae. Myxamoebae were grown in $660 \mathrm{ml}$ axenic medium or in $700 \mathrm{ml}$ suspensions of $K$. aerogenes in 21 Erlenmeyer flasks as described above. They were grown axenically unless otherwise indicated. The cells were harvested in the exponential phase of growth, washed with ice-cold distilled water, deposited on Millipore filters and allowed to differentiate as described by Hames \& Ashworth (1974). When additions were made to the pad diluting fluid (PDF; Garrod \& Ashworth, 1972), sufficient material was added to give a concentration $\mathrm{I} \cdot 3 \mathrm{I}$ times greater than the final concentration required : this allowed for the dilution of the PDF by the $0.5 \mathrm{ml}$ fluid in which the cells were deposited.

Harvesting and counting of spores. Spores were harvested from mature fruiting bodies by touching the spore masses with a fine capillary drawn from a Pasteur pipette: the spores collected in the capillary. Spores were picked from roo fruiting bodies taken at random, resuspended in I ml water (or Io mM-potassium phosphate buffer $\mathrm{pH} 6.5$, if the heat stability of the spores was to be tested ; North \& Campbell, 1976), and counted with a haemocytometer. Spore populations from fruiting bodies formed after certain treatments contained a small (less than 10\%) proportion of non-refractile cells : these were not scored as spores.

Testing strains for sensitivity to EACA. Suspensions of spores of different strains of $D$. discoideum were plated with $K$. aerogenes on SM agar containing 50 mM-EACA. In general, the bacterial suspension $(0.2 \mathrm{ml})$ was spread on the plate, and after 15 min a small volume (Io to $40 \mu \mathrm{l}$ ) of spore suspension was placed in the centre. Plates were incubated at $24{ }^{\circ} \mathrm{C}$ and observations made after 5 to 7 days : the sensitivity to EACA could be determined from the extent of fruiting body formation. Control plates lacking EACA were always set up in parallel.

Selection of haploid segregants from diploid strains. Haploid segregants were isolated from the diploid strains DP49 and DP59 (Williams, Kessin \& Newell, 1974a) by plating spores 
with $K$. aerogenes on SM agar containing cycloheximide $\left(400 \mu \mathrm{g} \mathrm{ml}^{-1}\right)$ or methanol $(2 \%$, $\mathrm{v} / \mathrm{v}$ ) at a density of about $\mathrm{IO}^{4}$ spores per plate, as described by Gingold \& Ashworth (I974). The size of the spores from resistant clones was examined microscopically to distinguish the haploid segregants from resistant diploids (which arise by mitotic recombination; Gingold \& Ashworth, 1974).

Characterization of strains. Strains were characterized on the basis of their ability to grow with $K$. aerogenes on SM agar containing cycloheximide $\left(400 \mu \mathrm{g} \mathrm{ml}^{-1}\right)$ or methanol $(2 \%$, $\mathrm{v} / \mathrm{v}$ ) at $22{ }^{\circ} \mathrm{C}$ and on SM agar plates at $27^{\circ} \mathrm{C}$, and also on the basis of pigmentation (whi and $b w n$; Williams et al., 1974a). The ability of strains to grow axenically was tested by adding approximately $10^{4}$ spores or myxamoebae to axenic medium ( $\mathrm{I} \mathrm{ml}$ ) containing streptomycin $\left(250 \mu \mathrm{g} \mathrm{ml}^{-1}\right.$; Watts \& Ashworth, 1970) in $100 \times 12 \mathrm{~mm}$ test-tubes. The tubes were rotated in a simple roller apparatus at $\mathrm{I} 5 \mathrm{rev} . \mathrm{h}^{-1}$ with the tubes at an angle of approximately $10^{\circ}$ to the horizontal. Growth was assessed during a period of up to 7 days incubation at $22{ }^{\circ} \mathrm{C}$.

\section{RESULTS}

\section{The EACA effect}

When axenically-grown myxamoebae of $D$. discoideum AX2 were incubated on Millipore filters at $24{ }^{\circ} \mathrm{C}$ in the presence of the antifibrinolytic agent EACA at concentrations above $40 \mathrm{mM}$, the cells aggregated in the same time ( 10 to $\mathrm{I} 2 \mathrm{~h}$ ) as did cells not exposed to EACA. However, subsequent morphological changes did not occur, and the cells either remained as large flat aggregates, or formed into smaller aggregates (Fig. I $d$ ). There was no formation of a tip. Clonal plating of suspensions of EACA-treated cells with $K$. aerogenes on SM agar gave $100 \%$ viable cells, even after $48 \mathrm{~h}$ on Millipore filters. Development was affected by concentrations of EACA as low as 5 to Io mM. The cells were able to form fruiting bodies but the spore masses of these were translucent rather than opaque. As the EACA concentration was increased, so the effect on development became more severe, and the final structure formed was less like the normal fruiting body.

Figure I shows the effect of increasing EACA concentrations on development, and the predominant types of structure observed are shown diagramatically in Fig. 2. Structure C apparently resulted from the folding-over of the spore mass, since the stalk was seen to be hooked around the spores. In both structure C and structure D, which had no spore mass, the presumed stalk was much broader than normal. Structure E resembled a normal slug to some extent, but was notable for the absence of a well-defined tip.

The increased translucence of the spore masses with increasing EACA concentrations suggested that the number of spores was reduced, although visual observation revealed that the fruiting body size remained approximately the same. This was confirmed by harvesting spores from fruiting bodies formed in the presence of different concentrations of the inhibitor (Fig. 3). In addition to this reduction in the number of spores, it was found that, although cells were picked only from the tip of the stalk, there was a small but significant number (up to $10 \%$ of the total) of non-refractile and apparently undifferentiated cells present at high EACA concentrations. The spore mass also became increasingly sticky.

An identical effect was observed with other, related amino acids (Table I). Two other antifibrinolytic agents, t-AMCHA and PAMBA (Okamoto et al., I968; Donner \& Housková, 1967), also blocked development of $D$. discoideum although aggregation was apparently normal. The concentrations required for a complete block after aggregation differed from that required with EACA (above 75 mM-t-AMCHA ; above Io mM-PAMBA). Only one of the homologues of EACA tested was effective in blocking development in a similar manner. 

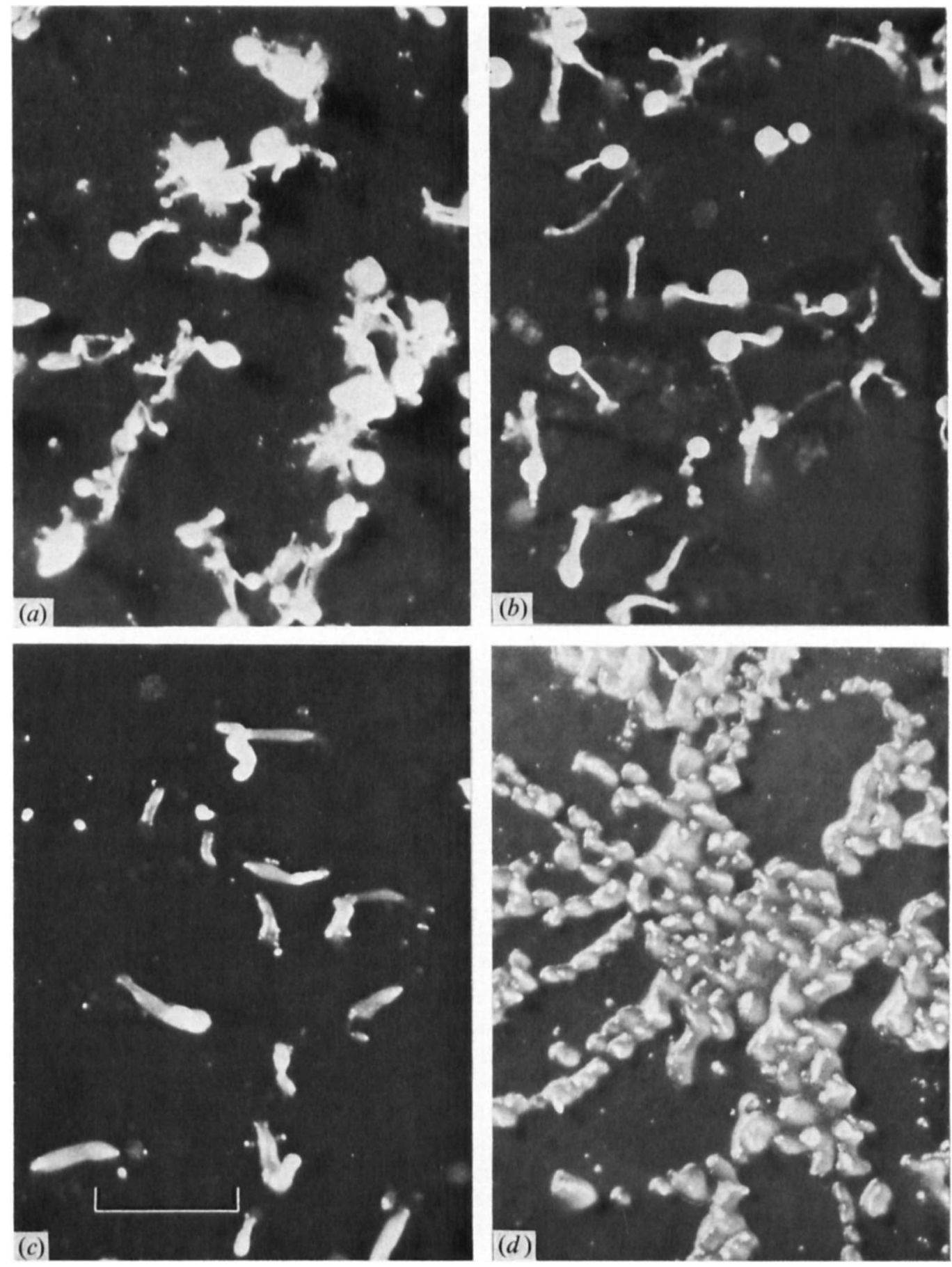

Fig. I. Effect of EACA on the development of axenically-grown myxamoebae of Dictyostelium discoideum strain AX2 on Millipore filters. The cells were incubated at $24{ }^{\circ} \mathrm{C}$ for $48 \mathrm{~h}$ in the presence of EACA at the following concentrations : $(a) \circ \mathrm{mM},(b) 17.5 \mathrm{mM},(c) 35 \mathrm{mM},(d) 50 \mathrm{~mm}$. Bar marker represents I $\mathrm{mm}$. 


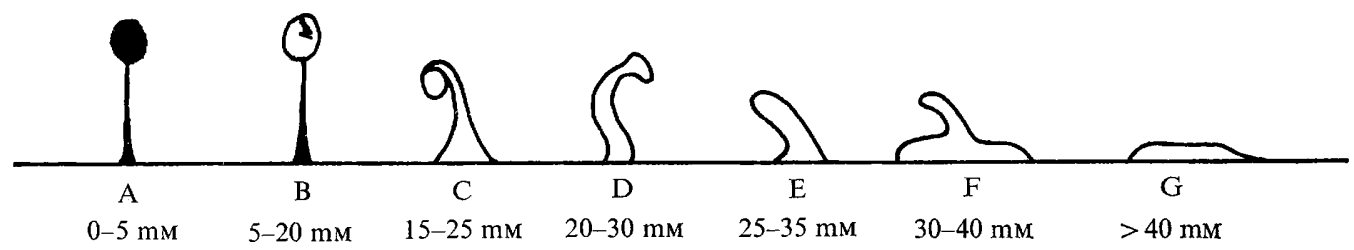

Fig. 2. Diagrammatic representations of the final structures formed by axenically-grown myxamoebae incubated at $24^{\circ} \mathrm{C}$ on Millipore filters with different concentrations of EACA.

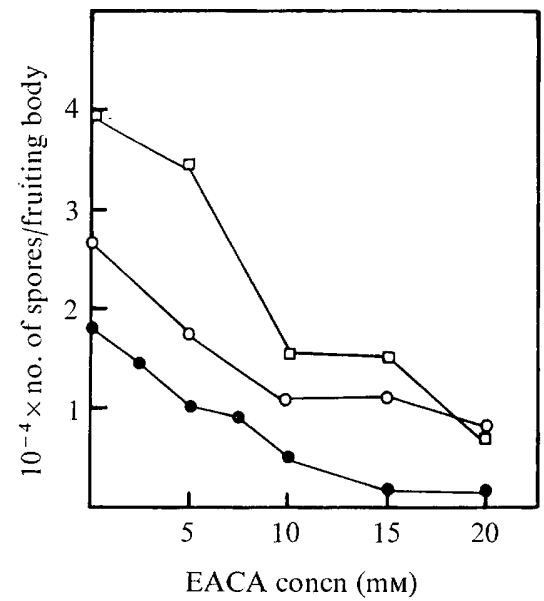

Fig. 3. Effect of EACA concentration on the number of spores per fruiting body. Spores were harvested from fruiting bodies formed by axenically-grown myxamoebae deposited on Millipore filters and incubated at $24{ }^{\circ} \mathrm{C}$ for $28 \mathrm{~h}(\mathrm{O}), 40 \mathrm{~h}(\mathrm{O})$ or $44 \mathrm{~h}(\square)$. The values are averages from $2 \times 100$ fruiting bodies $(\bullet, \square)$ or $5 \times 100$ fruiting bodies $(\bigcirc)$.

At low concentrations ( 5 to Io $\mathrm{mM}$ ), $\omega$-aminocaprylic acid (OACA) had the same effect as $40 \mathrm{~mm}$-EACA ; but, at higher concentrations it also inhibited aggregation. $\delta$-Aminovaleric acid was also an inhibitor of development but inhibited aggregation, which suggested that it may not have had the same effect as EACA. All the other $\omega$-aminocarboxylic acids tested allowed fruiting body formation when present at $50 \mathrm{~mm}$, although the morphology of the fruiting bodies and the exact time of their completion was sometimes found to differ from that of the controls. This was particularly so with lysine, which at high concentrations (I00 mM) caused very sparse development. None of the $\omega$-aminocarboxylic acids caused the specific block after aggregation observed with EACA.

At concentrations above $5 \mathrm{mM}$, norleucine ( $\alpha$-aminocaproic acid) completely inhibited development, including aggregation; and at lower concentrations (I to $5 \mathrm{mM}$ ), development was delayed and fruiting body formation became sparser with increasing concentration. No effect analogous to that of EACA was observed.

Neither lysine nor diaminopimelic acid was able to overcome the block caused by $50 \mathrm{~mm}$ EACA when they too were added to PDF at a concentration of $50 \mathrm{~mm}$. 
Table I. Effect of $\omega$-aminocarboxylic acids on the development of myxamoebae on Millipore filters at $24{ }^{\circ} \mathrm{C}$

Amino acids were added to PDF : for DAVA, the $\mathrm{pH}$ was adjusted to 6.5 with $\mathrm{NaOH}$. Axenicallygrown myxamoebae were deposited and incubated at $24{ }^{\circ} \mathrm{C}$. Observations were made over a period of $48 \mathrm{~h}$.

\begin{tabular}{|c|c|}
\hline Amino acid & Structure \\
\hline Glycine & $\mathrm{NH}_{2} \mathrm{CH}_{2} \mathrm{COOH}$ \\
\hline$\beta$-Alanine & $\mathrm{NH}_{2}\left(\mathrm{CH}_{2}\right)_{2} \mathrm{COOH}$ \\
\hline GABA & $\mathrm{NH}_{2}\left(\mathrm{CH}_{2}\right)_{3} \mathrm{COOH}$ \\
\hline DAVA & $\mathrm{NH}_{2}\left(\mathrm{CH}_{2}\right)_{4} \mathrm{COOH}$ \\
\hline EACA & $\mathrm{NH}_{2}\left(\mathrm{CH}_{2}\right)_{5} \mathrm{COOH}$ \\
\hline OACA & $\mathrm{NH}_{2}\left(\mathrm{CH}_{2}\right)_{7} \mathrm{COOH}$ \\
\hline Norleucine & $\mathrm{CH}_{3}\left(\mathrm{CH}_{2}\right)_{3} \mathrm{CHNH}_{2} \mathrm{COOH}$ \\
\hline Lysine & $\mathrm{NH}_{2}\left(\mathrm{CH}_{2}\right)_{4} \mathrm{CHNH}_{2} \mathrm{COOH}$ \\
\hline DAPA & $\mathrm{COOHCHNH}_{2}\left(\mathrm{CH}_{2}\right)_{3} \mathrm{CHNH}_{2} \mathrm{COOH}$ \\
\hline t-AMCHA & trans $-\mathrm{NH}_{2} \mathrm{CH}_{2} \mathrm{C}_{6} \mathrm{H}_{10} \mathrm{COOH}$ \\
\hline $\mathbf{B A} \mathbf{H}^{-}+$ & $\mathrm{NH}_{2} \mathrm{CH}_{2} \mathrm{C}_{6} \mathrm{H}_{4} \mathrm{C}$ \\
\hline
\end{tabular}

$\begin{array}{cc}\text { IO mM } & 50 \mathrm{mM} \\ + & + \\ + & + \\ + & + \\ + & - \\ + & + \\ + & - \\ + & - \\ + & + \\ + & + \\ + & + \\ + & +\end{array}$

Effect on fruiting $\dagger$

$\begin{array}{cc}\text { I0 } \mathrm{mM} & 50 \mathrm{mM} \\ + & + \\ + & + \\ + & + \\ + & - \\ + & - \\ - & - \\ - & - \\ + & + \\ + & + \\ + & - \\ - & -\end{array}$

$*+$, Aggregation took place as in controls; - , no aggregation after $48 \mathrm{~h}$.

$\dagger+$, Fruiting body formation took place, although not necessarily in the same manner as controls; - , no fruiting bodies formed.

$\ddagger \mathrm{No} \mathrm{NaCl}$ present.

\section{Effect of inhibitors on growth}

The lack of effect of EACA, t-AMCHA and PAMBA on the early stages of development suggested that they probably do not act as general inhibitors of metabolism. At concentrations that blocked development, neither EACA, PAMBA nor OACA had a significant effect on growth of myxamoebae in axenic medium or with suspensions of $K$. aerogenes. t-AMCHA was inhibitory, particularly when the myxamoebae were grown with bacteria, but this may have been a reflexion of the high concentration used $(75 \mathrm{mM})$.

This lack of effect on growth meant that cells could be grown with $K$. aerogenes, which was not sensitive, on SM agar to which an $\omega$-aminocarboxylic acid had been added, and the effect of the inhibitor on development could be observed.

\section{Time of effect of EACA}

To test whether the effect of EACA on post-aggregation events required the exposure of the cells to PDF containing the inhibitor over the whole period of incubation, cells were incubated in the absence of EACA for different times and were then transferred to PDF containing 50 mM-EACA. Even when cells were transferred as late as $8 \mathrm{~h}$ after deposition, EACA was still able to exert its full effect (Table 2). After Io $\mathrm{h}$ incubation, EACA had less effect, and failed to prevent fruiting body formation in cells exposed to it after $\mathrm{I} 6 \mathrm{~h}$.

When cells were transferred from EACA, the inhibitor affected development only if they were transferred at least $8 \mathrm{~h}$ after deposition. Even when post-aggregation development had been blocked, the removal of EACA still allowed some escape from inhibition. However, the longer the exposure to EACA the less able were the cells to recover and develop normally.

\section{Factors affecting the sensitivity to $E A C A$}

Ionic strength and $p H$. At $50 \mathrm{~mm}$, EACA was as effective in blocking post-aggregation development when it was dissolved in water as it was when dissolved in PDF, but the effect 
Table 2. Effect of exposure to EACA during a limited period of the development phase

Axenically-grown myxamoebae were deposited on Millipore filters supported by pads containing PDF with and without $50 \mathrm{~mm}$-EACA. At different times during incubation at $24^{\circ} \mathrm{C}$, the cells were transferred : cells incubated without EACA were transferred to EACA, and EACA-treated cells were transferred to PDF without EACA. Two transfer methods were used : (i) filters and cells were transferred directly to fresh pads and PDF; (ii) cells were washed from filters, disaggregated by trituration, collected by centrifugation, resuspended in water, and deposited on fresh filters, pads and PDF. The final structures formed were as shown in Fig. 2.

Structure observed after $36 \mathrm{~h}$ total incubation on filters

Time of transfer

$\begin{array}{rr}\text { To EACA : } & 6 \mathrm{~h} \\ & 8 \mathrm{~h} \\ & \mathrm{I} 0 \mathrm{~h} \\ & 12 \mathrm{~h} \\ 14 \mathrm{~h} \\ 16 \mathrm{~h} \\ 18 \mathrm{~h} \\ 20 \mathrm{~h} \\ 24 \mathrm{~h}\end{array}$

Not transferred

From EACA : $6 \mathrm{~h}$

$8 \mathrm{~h}$

Io h

$12 \mathrm{~h}$

$14 \mathrm{~h}$

$16 \mathrm{~h}$

I $8 \mathrm{~h}$

$20 \mathrm{~h}$

$24 \mathrm{~h}$

Not transferred

$\begin{array}{cc}\text { Direct transfer } & \text { Disaggregation } \\ \text { G } & \text { G } \\ \text { G } & \text { G } \\ \text { D, E } & \text { D, E, F } \\ \text { B } & \text { B, C } \\ \text { A } & \text { A, B } \\ \text { A } & \text { A } \\ \text { A } & \text { A } \\ \text { A } & \text { Recapitulation not possible } \\ \text { A } & \text { Recapitulation not possible } \\ \text { A } & - \\ \text { B } & \text { A } \\ \text { B } & \text { A } \\ \text { C, D, E } & \text { B } \\ \text { C, D, E } & \text { B } \\ \text { C, D, E } & \text { B } \\ \text { C, D, E } & \text { B } \\ \text { C, D, E } & \text { Miniature fruiting bodies } \\ \text { F } & \text { Miniature slugs and aggregates } \\ \text { G } & \text { G }\end{array}$

$\mathbf{G}$

was enhanced by high ionic strength. Salts were added to PDF containing EACA, and with final salt concentrations above $20 \mathrm{mM}$ (in addition to the $20 \mathrm{mM}-\mathrm{KCl}$ and $5 \mathrm{mM}_{-} \mathrm{MgCl}_{2}$ present in PDF), the concentration of EACA required to block development after aggregation decreased. For example, the presence of $40 \mathrm{mM}-\mathrm{NaCl}$ reduced the inhibitory concentration of EACA at $24{ }^{\circ} \mathrm{C}$ from $40 \mathrm{~mm}$ to less than $20 \mathrm{mM}$. This salt concentration did not affect the development of cells incubated without EACA. The enhancement was not apparently due to one specific ion or group of ions since it was observed with salts with different combinations of monovalent and divalent ions, e.g. $\mathrm{NaCl}, \mathrm{Na}_{2} \mathrm{SO}_{4}, \mathrm{NaNO}_{3}, \mathrm{MgCl}_{2}, \mathrm{KCl}$, $\mathrm{NH}_{4} \mathrm{Cl}$.

The effect of the ionic strength was particularly important in the case of PAMBA. The product supplied by VEB Arzneimittelwerk was in an isotonic solution, and so PDF containing PAMBA from this source also contained $\mathrm{NaCl}$. For this reason, it was apparently more effective than the solid PAMBA supplied by May \& Baker.

At $50 \mathrm{~mm}$, EACA always produced a block after aggregation in the $\mathrm{pH}$ range 5.8 to 8.5 .

Temperature. As the incubation temperature was lowered, so the concentration of EACA required to prevent post-aggregation development increased (Fig. 4). Cells incubated at $19{ }^{\circ} \mathrm{C}$ in the presence of concentrations of EACA which inhibited at $24{ }^{\circ} \mathrm{C}$, escaped inhibition and formed the structures observed with lower EACA concentrations at $24{ }^{\circ} \mathrm{C}$. For example, with 50 mM-EACA translucent fruiting bodies (structure B, Fig. 2) were formed. A temperature dependence was also observed for the inhibitory effects of t-AMCHA, PAMBA and OACA. Although at $24{ }^{\circ} \mathrm{C}, 50 \mathrm{mM}-\mathrm{OACA}$ completely inhibited aggregation, 


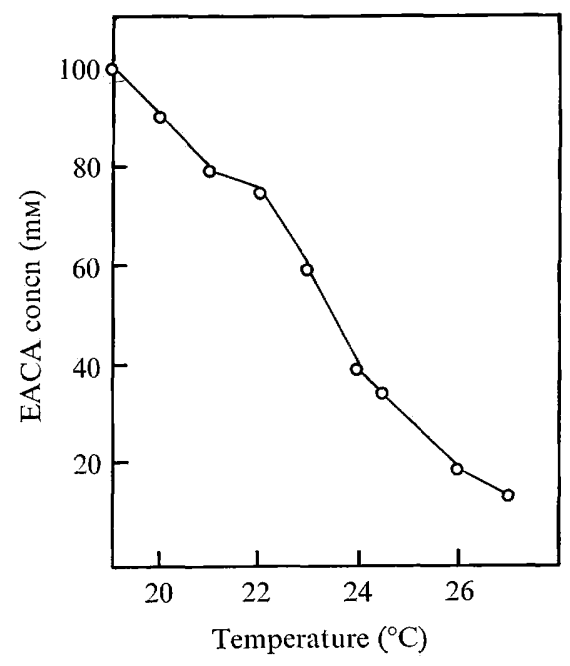

Fig. 4. Effect of temperature on the concentration of EACA required to prevent further.development of axenically-grown cells after aggregation. The concentrations are the lowest at which only structure G (Fig. 2) was formed.

this inhibition was removed by lowering the temperature to $19{ }^{\circ} \mathrm{C}$, and at the latter temperature $50 \mathrm{~mm}$-OACA had the same effect as $50 \mathrm{~mm}$-EACA at $24^{\circ} \mathrm{C}$.

The temperature routinely used in these experiments $\left(24^{\circ} \mathrm{C}\right)$ was chosen because it allowed EACA to block development at a lower concentration than at $22{ }^{\circ} \mathrm{C}$ (the growth temperature), but also allowed temperature-sensitive growth mutants which are unable to grow at higher temperatures to be studied.

Growth conditions for myxamoebae. In addition to extracellular factors obtaining during incubation of cells on Millipore filters, the sensitivity to EACA was also dependent on the manner in which the cells were grown. Cells grown in axenic medium were inhibited by 40 mm-EACA at $24{ }^{\circ} \mathrm{C}$ (Fig. 4); but, if glucose was added to the growth medium, the concentration of EACA necessary to achieve inhibition of fruiting body formation increased, provided the cells were harvested during the exponential growth phase. Cells grown in the presence of $86 \mathrm{~mm}$-glucose escaped complete post-aggregation inhibition at EACA concentrations of less than $80 \mathrm{~mm}$. However, if the cells were allowed to enter stationary growth phase before harvesting, the inhibitory EACA concentration was only 30 to $40 \mathrm{mM}$.

The sensitivity to EACA of cells grown in association with $K$. aerogenes in shaken culture varied from experiment to experiment, and concentrations of the inhibitor of between $40 \mathrm{~mm}$ and $100 \mathrm{~mm}$ were required to block post-aggregation development. When cells were plated in association with bacteria on SM agar containing EACA, a concentration of $50 \mathrm{~mm}$ always prevented development after aggregation.

\section{The relationship between sensitivity to $E A C A$ and the ability to grow axenically}

The effect of EACA was first observed with strain AX2 which was isolated for its ability to grow axenically (Watts \& Ashworth, 1970). Strain NC4 (Raper, 1935), the non-axenic strain to which AX2 can be traced, was not sensitive to EACA. A difference in sensitivity between the two strains was also observed with PAMBA, t-AMCHA, and OACA. Concentrations of all four compounds (EACA, roo mM; PAMBA, $50 \mathrm{mM}$; t-AMCHA, $80 \mathrm{mM}$; OACA, $50 \mathrm{~mm}$ ) 
Table 3. Sensitivity of various strains to EACA

$\begin{array}{lccc}\text { Strain } & \text { Reference* } & \text { Genotype } \dagger & \text { Sensitivity to EACA } \$ \\ \text { NC4 } & \text { I } & + & \mathrm{R} \\ \text { VI2 } & 2 & + & \mathrm{R} \\ \text { TS12 } & 3 & + & \mathrm{R} \\ \text { NPI4 } & 4 & + & \mathrm{R} \\ \text { X9 } & 4 & + & \mathrm{R} \\ \text { AX2 } & 5 & \text { axe } & \mathrm{S} \\ \text { AX3 } & 6 & \text { axe } & \mathrm{S} \\ \text { X2 } & 4 & \text { axe } & \mathrm{S} \\ \text { X20 } & 4 & \text { axe } & \mathrm{S} \\ \text { G82 } & 7 & \text { axe } & \mathrm{S} \S \\ \text { G88 } & 8 & \text { axe } & \mathrm{S} \S \\ \text { DP49 } & 4 & \text { axe } /+ & \mathbf{R} \\ \text { DP59 } & 4 & \text { axe } /+ & \mathbf{R}\end{array}$

* I, Raper (1935) ; 2, Erdos, Raper \& Vogen (1973) ; 3, Katz \& Sussman (1972) ; 4, Williams et al. (1974a); 5, Watts \& Ashworth (1970) ; 6, Loomis (197I) ; 7, E. Gingold, growth temperature-sensitive, cycloheximideresistant mutant from AX2; 8, Gingold (1974).

$\dagger+$, Wild type, incapable of axenic growth; axe, able to grow axenically; axe $/+$, diploid heterozygous for axenic markers, incapable of axenic growth.

$\ddagger R$, Resistant, formed normal fruiting bodies in the presence of $50 \mathrm{mm-EACA}$ at $24{ }^{\circ} \mathrm{C} ; \mathrm{S}$, sensitive, failed to form fruiting bodies in the presence of $50 \mathrm{~mm}$-EACA at $24{ }^{\circ} \mathrm{C}$.

$\S$ From observations of development of axenically-grown cells on Millipore filters : growth on agar plates at $24{ }^{\circ} \mathrm{C}$ was poor.

that inhibited bacterially-grown cells of AX2 allowed fruiting bodies to form from NC4 cells. It is noteworthy that, like $\mathrm{AX} 2, \mathrm{NC}_{4}$ was sensitive to norleucine, which suggests that the action of this amino acid was not related to that of EACA. $\delta$-Aminovaleric acid (DAVA) did not block the development of $\mathrm{NC} 4$ cells, and in view of its effect on AX2 cells (Table I) it is possible that DAVA may have had an effect related to that of EACA.

A second axenic strain, $\mathrm{AX} 3$, independently isolated (Loomis, $197 \mathrm{I}$ ), was also sensitive to EACA, PAMBA, t-AMCHA and OACA at similar concentrations to those that inhibited $\mathrm{AX} 2$ cells. The inhibition of $\mathrm{AX} 3$ was also temperature-dependent. A number of other strains were tested for their sensitivity to EACA ; all non-axenic strains were able to form fruiting bodies in the presence of $50 \mathrm{~mm}$-EACA at $24^{\circ} \mathrm{C}$, but all axenic strains were inhibited (Table 3 ). The presence or absence of any other known marker was not a requirement for sensitivity.

The ability to grow axenically is a recessive character (Williams, Kessin \& Newell, 1974b), and so diploid strains constructed between non-axenic and axenic haploid strains are incapable of axenic growth. Two such diploids were tested for their sensitivity to EACA, and both were resistant (Table 3). DP49 and DP59 were derived from the non-axenic strain TSI 2 and the axenic strains NP59 and NP58 respectively (Williams et al., I974a). TSI2 was tested and was resistant to EACA ; but strain MNAI isolated from DP49 in this laboratory and having the identical phenotype to NP59 (methanol resistance, temperature-sensitive growth, brown pigmentation, axenic growth), was sensitive to EACA.

Proposed markers for axenic growth have been assigned to two linkage groups, axe $A$ to linkage group II and $a x e B$ to linkage group III (Williams et al., 1974a). In an attempt to determine whether one or both of these markers were required for EACA sensitivity, we isolated haploid segregants of DP49 and DP59 in which either the axenic linkage group II or both axenic linkage groups II and III were present (Table 4). The presence of these linkage groups was assigned on the basis of the inheritance of other markers. Strains with axe $A$ only were selected as methanol-resistant strains which grew at $27^{\circ} \mathrm{C}$, and those with both markers 


\section{Table 4. Haploid segregants isolated from DP49 and DP59}

Segregants from DP49 were selected initially on SM agar plus methanol (2\%, v/v) and those from DP59 on SM agar plus cycloheximide $\left(400 \mu \mathrm{g} \mathrm{ml}^{-1}\right)$.

\begin{tabular}{|c|c|c|c|c|c|c|c|c|c|c|}
\hline & & & & & inkag & group & & & & \\
\hline & Derived from & I & & II & & & I & & IV & est \\
\hline Diploid & & & & & & & & & & \\
\hline & C TSI 2 & $\operatorname{cyc} A I$ & $t s g D r 2$ & + & whi & + & + & + & + & \\
\hline $2749(2539)$ & NP59 (NP58) & + & + & $\operatorname{acr} A g(A 8)$ & + & $\operatorname{axeAI}$ & $a x e B I$ & $t s g A I$ & $b w n$ & \\
\hline Haploid segregants & & & & & & & & & & \\
\hline Nom & & + & + & acr $A 9$ & + & $\operatorname{axe} A I$ & + & + & + & 3 \\
\hline 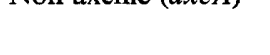 & DP49 & + & + & $\operatorname{acr} A 9$ & + & axeAr & + & + & $b w n$ & 7 \\
\hline & & $c y c A I$ & + & $\operatorname{acr} A 8$ & + & $\operatorname{axe} A I$ & + & + & + & 4 \\
\hline & DP59 & $\operatorname{cyc} A I$ & + & $\operatorname{acr} A 8$ & + & $\operatorname{axeAI}$ & + & + & $b w n$ & 5 \\
\hline Axenic $(a x e A, a x e B)$ & DP49 & + & + & $\operatorname{acr} A 9$ & + & axeAr & $a x e B I$ & $\operatorname{tsg} A I$ & $b w n$ & $\mathbf{I}$ \\
\hline
\end{tabular}

Gene symbols : cycAr, growth in the presence of cycloheximide $\left(400 \mu \mathrm{g} \mathrm{ml}^{-1}\right) ; t s g D_{I 2}, t s g A I$, displays temperature-sensitive growth; $\operatorname{acr} A 8, \operatorname{acr} A 9$, growth in the presence of acriflavin $\left(100 \mu \mathrm{g} \mathrm{ml}^{-1}\right)$ and methanol $(2 \%, v / v) ; a x e A I$, axeBI, growth in axenic medium if both markers present; whi, white spore; bwn, formation of brown pigment.

as methanol-resistant strains unable to grow at $27^{\circ} \mathrm{C}$. Attempts to isolate strains which possessed the axeB marker only (methanol-sensitive, white, non-leaky temperature-sensitive growth) were unsuccessful.

All of the strains tested which possessed the axe $A$ but not the $a x e B$ marker were unable to form fruiting bodies in the presence of EACA. However, their sensitivity to EACA was intermediate between that of strains AX2 and NC4. Thus, in the presence of 50 mM-EACA, I4 out of 19 strains tested formed finger-like structures (structure D, Fig. 2). The five remaining strains were apparently as sensitive to EACA as was strain AX2, but also showed a markedly more temperature-sensitive developmental pattern such that at $24^{\circ} \mathrm{C}$ in the absence of EACA fruiting body construction did not take place. We feel confident, therefore, that the sensitivity to EACA shown by these strains is due, not only to the presence of the axeA marker, but also to the presence of another marker not detectable in the strain (DP59) from which these five were derived.

All strains with the axeA marker only were unable to grow axenically. The one haploid strain isolated with both axeA and axeB markers was able to grow axenically, and was sensitive to EACA to the same degree as was strain AX2. These observations were consistent with the view that axeA confers sensitivity to EACA but that for complete sensitivity (as shown by strain $\mathrm{AX} 2$ ), the presence of a second marker, such as axe $B$, is also required; although more detailed genetic analysis will be necessary to show that the markers for EACA sensitivity and those for axenic growth are allelic.

In a preliminary investigation of the possibility of isolating mutants with altered sensitivity to EACA, a strain characterized as possessing the axeA marker only (MNAI3, derived by haploidization of DP49), which formed fingers (structure D, Fig. 2) in the presence of 50 mM-EACA, was mutagenized with NTG as described by Yanagisawa, Loomis \& Sussman 
(1967). Mutant strains that were able to form fruiting bodies in the presence of 50 mM-EACA arose at a frequency of approximately one in 1000 amongst the survivors. Mutants were also isolated whose morphology in the presence of 50 mM-EACA was the same as that observed with AX2 but, in most cases, these strains were unable to complete development in the absence of EACA. However, we isolated two strains (MNF5, MNF20) that displayed this phenotype only in the presence of EACA. In addition to their increased sensitivity to EACA, these strains were also capable of axenic growth, unlike the parent strain (MNAI3). This suggests that they arose as a result of mutation in the proposed axe $B$ gene.

\section{DISCUSSION}

On the basis of the results presented in this paper, the effect of EACA and related $\omega$-aminocarboxylic acids has been characterized as an inhibition of the development of $D$. discoideum after aggregation that is temperature dependent and related to the presence of genetic markers for axenic growth in a particular strain. A mutant of NC4 unable to develop after the aggregation stage was isolated in 1953 (Sussman \& Sussman, 1953) and had a phenotype similar to that shown by strain AX2 developing in the presence of EACA. The EACA effect was specific with regard to the inhibitory compound since similar amino acids (glycine, $\beta$-alanine, $\gamma$-aminobutyric acid and lysine) could be added to PDF without producing the same effect. This ruled out the possibility that the effect was due to a simple change in the ionic conditions, as did the fact that both PAMBA and OACA inhibited at concentrations that were much lower than those needed with EACA and t-AMCHA. The time of the effect also appeared to be specific ; EACA had to be present during the period 8 to $\mathrm{I} 6 \mathrm{~h}$ after deposition on Millipore filters to exert any effect. At this time the aggregated cells would normally be starting the series of morphological changes resulting in fruiting body construction. EACA has no effect on biochemical changes occurring early in development, but severely inhibits later events (North \& Campbell, 1976).

With the exception of OACA, those amino acids that blocked development after aggregation are potent inhibitors of fibrinolysis (Okamoto et al., 1968). In that process they act by inhibiting the proteolytic activation of plasminogen or the action of plasmin on fibrin (Brockway \& Castellino, I97I ; Iwamoto, 1975). However, no other proteolytic inhibitors have been found which have the same effect on $D$. discoideum development (unpublished observations) and so the $\omega$-aminocarboxylic acids may not necessarily act by inhibition of a proteolytic event. Reports of effects of EACA on other systems have been made, for example, the inhibition of the response of lymphocytes to phytohaemagglutinin (Hirschhorn et al., I97I) and an effect on potassium metabolism in dogs (Carroll \& Tice, I966).

Whatever the mechanism for EACA inhibition of development, the difference in sensitivities between different strains must be explained. Although differences between NC4 and AX2 cells in sensitivity to certain agents have been noted previously (e.g. Weeks \& Weeks, 1975), this is the first case in which a difference, apart from the ability to grow axenically, has been shown to be related to the presence of the genetic markers for axenic growth. It is anticipated that the sensitivity to EACA may provide a useful characteristic for the isolation of strains possessing axenic growth markers. In particular it may be possible to characterize strains carrying the axeA marker. The differences in sensitivity might also help to establish the molecular basis of the ability to grow axenically. 
We are particularly indebted to Dr P. C. Newell and to Dr K. L. Williams for providing many of the strains used in this study. We would like to thank Miss Leonie Smith for excellent technical assistance, and the Science Research Council for financial support. M. J. N. was a Science Research Council Postdoctoral Research Fellow.

\section{REFERENCES}

Ablondi, F. B., Hagan, J. J., Philips, M. \& De Renzo, E. C. (1959). Inhibition of plasmin, trypsin and the streptokinase-activated fibrinolytic system by $\epsilon$-aminocaproic acid. Archives of Biochemistry and Biophysics 82, I53-160.

AlkJAersig, N., FletCher, A. P. \& Sherry, S. (I959). 6 -Aminocaproic acid : an inhibitor of plasminogen activation. Journal of Biological Chemistry 234, 832-837.

Brockway, W. J. \& Castellino, F. J. (I97I). The mechanism of the inhibition of plasmin activity by $\epsilon$ aminocaproic acid. Journal of Biological Chemistry 246, 464I-4647.

CARRoll, H. J. \& TICE, D. A. (I966). The effects of epsilon aminocaproic acid upon potassium metabolism in the dog. Metabolism: Clinical and Experimental 15, 449-457.

DONNER, L. \& HousKovÁ, J. (1967). On the action of mechanism of some fibrinolysis inhibitors. Thrombosis et diathesis haemorrhagica $\mathbf{1 8}, 439-446$.

ERdos, G. W., RAPER, K. B. \& VoGEN, L. K. (1973). Mating types and macrocyst formation in Dictyostelium discoideum. Proceedings of the National Academy of Science of the United States of America $7 \mathbf{0}$, I828-I830.

EVERY, D. \& AshWORTH, J. M. (1975). Rates of accumulation of glycosidase activities during growth and differentiation of Dictyostelium discoideum. Biochemical Journal 148, I6I-167.

Garrod, D. \& Ashworth, J. M. (1972). Effect of growth conditions on development of the cellular slime mould, Dictyostelium discoideum. Journal of Embryology and Experimental Morphology 28, 463-479.

Garrod, D. \& AshworTh, J. M. (1973). Development of the cellular slime mould Dictyostelium discoideum. Symposia of the Society for General Microbiology 23, 407-435.

GerISCH, G. (1960). Zellfunktionen und Zellfunktionswechsel und die Entwicklung von Dictyostelium discoideum. I. Zellagglutination und Induktion der Fruchtkörperpolarität. Wilhelm Roux Archiv für Entwicklungs-mechanik der Organismen 152, 632-654.

GINGOLD, E. B. (1974). Stability of diploid clones of the cellular slime mould Dictyostelium discoideum. Heredity 33, 420-423.

Gingold, E. B. \& AshWORTH, J. M. (1974). Evidence for mitotic crossing-over during the parasexual cycle of the cellular slime mould Dictyostelium discoideum. Journal of General Microbiology 84, 70-78.

HAMEs, B. D. \& Ashworth, J. M. (1974). The metabolism of macromolecules during the differentiation of myxamoebae of the cellular slime mould Dictyostelium discoideum containing different amounts of glycogen. Biochemical Journal I42, 30I-315.

Hirschhorn, R., Grossman, J., Troll, W. \& Weissmann, G. (1971). The effect of epsilon amino caproic acid and other inhibitors of proteolysis upon the response of human peripheral blood lymphocytes to phytohemagglutinin. Journal of Clinical Investigation 50, I 206-I 2 I 2

Iwamoto, M. (1975). Plasminogen-plasmin system. IX. Specific binding of tranexamic acid to plasmin. Thrombosis et diathesis haemorrhagica 33, 573-585.

Katz, E. R. \& Sussman, M. (1972). Parasexual recombination in Dictyostelium discoideum: selection of diploid heterozygotes and stable segregants. Proceedings of the National Academy of Sciences of the United States of America 69, 495-497.

Loomis, W. F. (1971). Sensitivity of Dictyostelium discoideum to nucleic acid analogues. Experimental Cell Research 64, 484-486.

Loomis, W. F. (1975). Dictyostelium discoideum : a Developmental System. New York: Academic Press.

North, M. J. \& CAMPBell, A. J. (1976) The effect of $\epsilon$-aminocaproic acid on biochemical changes in the development of the cellular slime mould Dictyostelium discoideum. Journal of General Microbiology 96, $77-85$.

Okamoto, S., Oshiba, S., Mihara, H. \& Okamoto, U. (I968). Synthetic inhibitors of fibrinolysis : in vitro and in vivo mode of action. Annals of the New York Academy of Sciences 146, 414-429.

RAPER, K. B. (1935). Dictyostelium discoideum, a new species of slime mould from decaying forest leaves. Journal of Agricultural Research 50, I35-I 47.

Sussman, M. (1966). Biochemical and genetic methods in the study of cellular slime mould development. In Methods in Cell Physiology, vol. 2, pp. 397-410. Edited by D. M. Prescott. New York: Academic Press.

SUSSMAN, R. R. \& SUSSMAN, M. (I953). Cellular differentiation in Dictyosteliaceae : heritable modifications of the developmental pattern. Annals of the New York Academy of Sciences 56, 949-960.

WATTS, D. J. \& AshworTH, J. M. (1970). Growth of myxamoebae of the cellular slime mould Dictyostelium discoideum in axenic culture. Biochemical Journal rr9, 171-174. 
WeEks, C. \& Weeks, G. (1975). Cell surface changes during the differentiation of Dictyostelium discoideum: interaction of cells with concanavalin A. Experimental Cell Research 92, 372-382.

Williams, K. L., Kessin, R. H. \& Newell, P. C. (1974a). Parasexual genetics of Dictyostelium discoideum : mitotic analysis of acriflavin resistance and growth in axenic medium. Journal of General Microbiology 84, 59-69.

Williams, K. L., Kessin, R. H. \& Newell, P. C. (1974 b). Genetics of growth in axenic medium of the cellular slime mould Dictyostelium discoideum. Nature, London 247, I42-143.

Yanagisawa, K., Loomis, W. F. \& Sussman, M. (1967). Developmental regulation of the enzyme UDPgalactose polysaccharide transferase. Experimental Cell Research 46, 328-334. 